DOI: http://dx.doi.org/10.18203/2320-1770.ijrcog20195647

\title{
Awareness, attitude and practice of contraception amongst post-partum women in a rural tertiary care hospital, Telangana, India
}

\author{
Murty V. R. Nabhi*, Madhuri M., Vijayalakshmi G., Vasantha K., Kavitha K., Uma B.
}

Department of Obstetrics and Gynecology, Bhaskar Medical College, Moinabad, Hyderabad, Telangana, India

Received: 10 December 2019

Accepted: 19 December 2019

*Correspondence:

Dr. Murty V. R. Nabhi,

E-mail: nabhivrmurty@gmail.com

Copyright: () the author(s), publisher and licensee Medip Academy. This is an open-access article distributed under the terms of the Creative Commons Attribution Non-Commercial License, which permits unrestricted non-commercial use, distribution, and reproduction in any medium, provided the original work is properly cited.

\begin{abstract}
Background: India was the first country in the world to start the National Family Welfare Program in 1951. But population stabilization has been a difficult target to achieve and by the year 2028, our population is expected to surpass that of China. This study was conducted among puerperal women delivered at our hospital to know their awareness about various methods of contraception and willingness to practice any of these methods.

Methods: This cross-sectional interview-based study was conducted in the department of obstetrics and gynecology at Bhaskar Medical College and Hospital, Moinabad, Hyderabad from September 2015 to August 2016. The study sample were women who delivered in our hospital and a set questionnaire was used.

Results: A total of 502 women in the post-partum period were included in the study.88.85\% women were aware of any modern contraceptive. $30.85 \%$ of these women were aware of only the surgical method, i.e. sterilization; and another $58 \%$ women were aware of temporary methods also. Most of them knew about multiple methods, but tubectomy was the main method was known to the maximum (78\%). As the literacy levels rose, awareness about temporary methods and male sterilization also increased. $70 \%$ of the study population were not aware of free availability of all these methods at Government hospitals and at our hospital.80.5\% of these women were motivated after this study to accept a contraceptive method.

Conclusions: There is a great unmet demand for contraception among rural women in India. Proper dissemination of the information about free availability of these methods by rural health workers, hospital staff and making these accessible in the peripheral areas of the country will help these couples. Providing oral, written and visual information to all the pregnant women at each ante-natal visit will be additional methods.
\end{abstract}

Keywords: Acceptance, Attitude, Awareness, Contraception, Post-partum

\section{INTRODUCTION}

India is the second most populated country in the world with approximately 1.33 billion people in 2017 . India's population growth rate is $1.2 \%$ in 2013 and fertility rate is 2.3 during 2015 to 2020 as compared to China's $0.5 \%$ and 1.7 respectively. ${ }^{1,2}$ Our population is expected to overtake that of China in 2028. ${ }^{1}$ Burgeoning population with limited landmass will put increasing burden on the economic resources and development of the nation. WHO defined family planning as "a way of thinking and living that is adopted voluntarily, upon the basis of knowledge, attitude and responsible decisions by individuals and couples, in order to promote the health and welfare of the family group and thus contribute effectively to the social development of a country"? India was the first country in the world to start the National family planning programme in the early 1950 s. $^{3}$ Despite innovative modifications of the programme over the decades (maternal and child health programme; reproductive and child health programme) population stabilisation appears to be a difficult target to achieve. 
Slogans like "delay the first, space the next" by the Health and Family Welfare department of Government of India still have to achieve the desired results. Delaying the first pregnancy reduces need for termination of unintended pregnancy and risks of sepsis and associated maternal morbidity in a developing country like ours.

When the inter-pregnancy interval is less than 2 years, infant mortality chances are reported to be twice that when it is more than 3 years. 4 And when it is less than 6 months, these women were at increased risk of maternal deaths, ante-partum haemorrhage, PROM and anaemia.5 Increased contraceptive use in postpartum period substantially reduces maternal and infant mortality by preventing unplanned and unwanted pregnancies, spacing to at least 2 years after previous delivery. ${ }^{6}$ Also the largest proportion of women with unmet need of contraception are found in the first year after delivery. ${ }^{7}$ The dynamics of contraceptive use among women in post-partum period and one year hence is of interest at the family planning program level, as the delay in contraceptive use until the return of menstruation might increase unwanted pregnancy. ${ }^{8}$

The puerperal stay in the hospital offers the parturient lady family planning counselling by the health care professionals as well as by the relatives and friends. At this period, the parturient is also receptive to advice about her health, health of child and family. And the husband and relatives who have a major role in deciding about family size are also available for counselling.

\section{METHODS}

This cross-sectional interview-based study was conducted in the department of obstetrics and gynaecology at Bhaskar Medical College and Hospital, Moinabad, Hyderabad from September 2015 to August 2016.The study sample comprised of 502 puerperal women who delivered in our department.

According to NFHS-4 data, the prevalence rate of contraceptive use among currently married women aged $15-49$ years is $46 \%$ in rural areas (average $47.8 \%$ ). Assuming $46 \%$ prevalence with $95 \% \mathrm{CI}$ and relative precision of $10 \%$, the sample size was calculated to be 450. The study population was explained about the objectives of the study and an informed consent was obtained. A questionnaire was prepared about sociodemographic characteristics, literacy levels, awareness, attitude and acceptance of the various methods of contraception. After collecting the data as per the questionnaire, they were offered health education, counselling and contraceptive services.

\section{Statistical analysis}

The data was entered in Microsoft excel and analysed with the help of SPSS version 16. Statistical significance (P-value) was calculated using Pearson Chi square test.

\section{RESULTS}

A total of 502 puerperal women were included in the study. Table 1 shows the socio-demographic characteristics of the women under study. $55.4 \%$ of them were in the age-group of 21-30 years. $48.4 \%$ were uniparous while $10.2 \%$ had 3 children. $85.9 \%$ of the group were literate as compared to national average of $68.4 \%$ women in $2015-12 .^{2} 49.0 \%$ of our women had schooling of 10 years or more as compared to national average of $35.7 \%$. $^{2}$

Table 1: Socio-demographic profile of women under study $(n=502)$.

\begin{tabular}{|c|c|c|}
\hline Parameter & No. of puerperal women & $\%$ \\
\hline \multicolumn{3}{|l|}{ Age in years } \\
\hline$<20$ & 218 & 43.4 \\
\hline $21-30$ & 278 & 55.4 \\
\hline $31-40$ & 06 & 1.2 \\
\hline \multicolumn{3}{|l|}{ Parity } \\
\hline Para 1 & 244 & 48.6 \\
\hline Para 2 & 206 & 41.0 \\
\hline Para 3 & 51 & 10.2 \\
\hline Para 4 & 01 & 0.2 \\
\hline \multicolumn{3}{|l|}{ Education } \\
\hline Illiterate & 71 & 14.1 \\
\hline $7^{\text {th }}$ & 83 & 16.5 \\
\hline $10^{\text {th }}$ & 175 & 34.9 \\
\hline $12^{\text {th }}$ & 104 & 20.7 \\
\hline$>=$ degree & 69 & 13.8 \\
\hline \multicolumn{3}{|l|}{ Occupation } \\
\hline Homemaker & 374 & 74.5 \\
\hline Labourer/Farmer & 104 & 20.7 \\
\hline Skilled worker & 10 & 2.0 \\
\hline Others & 14 & 2.8 \\
\hline \multicolumn{3}{|l|}{ Religion } \\
\hline Hindu & 298 & 59.4 \\
\hline Muslim & 142 & 28.3 \\
\hline Christian & 61 & 12.1 \\
\hline Others & 01 & 0.2 \\
\hline
\end{tabular}

Most of the families of this rural area were either farmers or labourers in their farmlands $(95 \%)$ with only a notional income and was not quantifiable.

So, scoring of the socio-economic status as per BG Prasad scales for rural population could not be done. $59.6 \%$ of the women were Hindus and $28.2 \%$ were Muslims.

A total $30.85 \%$ of the total study population were aware of only the permanent method of contraception. And about $41.3 \%$ of these 155 had never heard that sterilisation is there for the males. $58 \%$ of the total women studied (504) were aware of any temporary or spacing methods of contraception (Table 2). 
Table 2: Awareness of any modern contraceptive $(\mathbf{n}=\mathbf{5 0 2})$.

\begin{tabular}{|lll|}
\hline Awareness & $\begin{array}{l}\text { No. of puerperal } \\
\text { women }\end{array}$ & $\%$ \\
\hline No & 56 & 11.15 \\
\hline Yes & 446 & 88.85 \\
\hline Sterilization & 155 & 30.85 \\
\hline Only female sterilization & 64 & 41.3 \\
\hline $\begin{array}{l}\text { Both male and female } \\
\text { sterilization }\end{array}$ & 91 & 58.7 \\
\hline Temporary methods & 291 & 58.0 \\
\hline
\end{tabular}

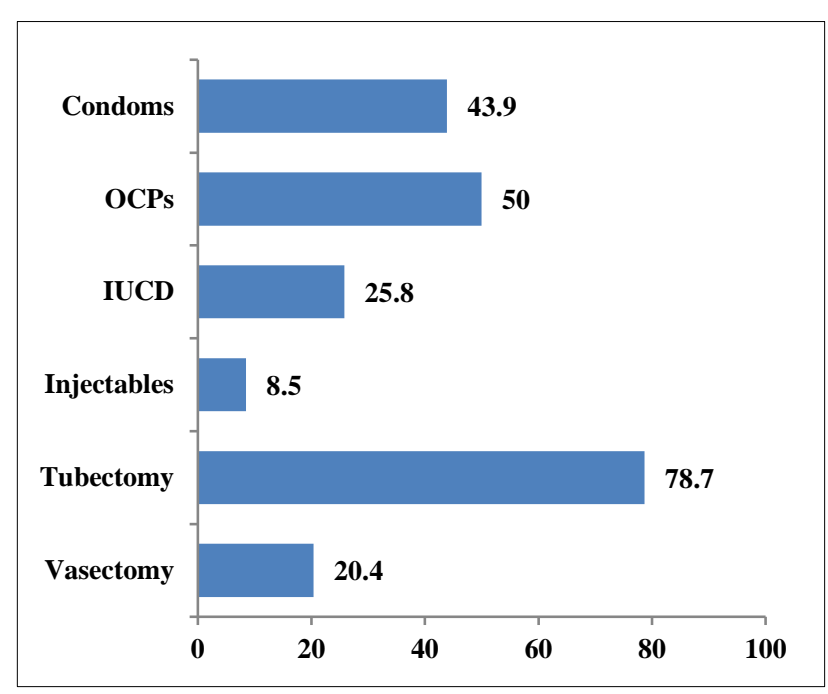

Figure 1: Awareness of various methods of contraception $(\%)(n=446)$.

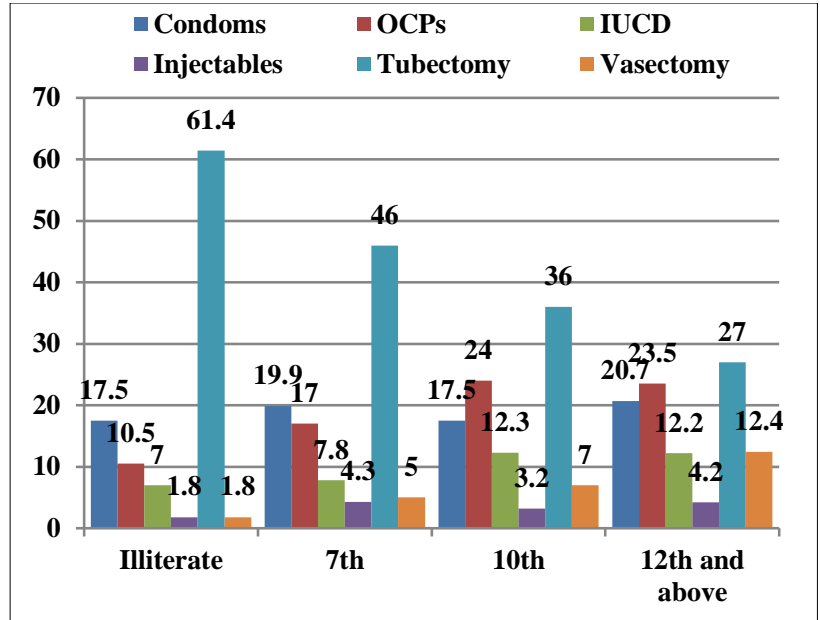

Figure 2: Literacy levels and awareness of modern contraceptive methods.

Most of the study population knew about multiple methods. But tubectomy was the main method known to the maximum (78.7\%) (Figure 1). As literacy levels increased in the study population, awareness about all the various methods of contraception increased- particularly about the temporary methods and vasectomy (Figure 2). This was found statistically significant as calculated using Pearson Chi-square test (Table 3).

A total 291 of the study population were aware of temporary contraceptive methods. Multiple reasons given for not using such methods. Most common reason was lack of awareness of benefits of use and next common reason was desire for further child-bearing (Figure 3).

Table 3: Literacy levels and awareness of modern contraceptives $(n=502)$.

\begin{tabular}{|llllll|}
\hline & Illiterate $(\mathbf{n}=\mathbf{7 1})$ & $\mathbf{7}^{\text {th }}(\mathbf{n}=\mathbf{8 3})$ & $\mathbf{1 0}^{\text {th }}(\mathbf{n}=\mathbf{1 7 5})$ & $\mathbf{1 2}^{\text {th }}(\mathbf{n}=\mathbf{1 7 3})$ & $\mathbf{p}$-value \\
\hline Condoms & 10 & 28 & 60 & 98 & 0.01 \\
\hline OCPs & 06 & 24 & 82 & 111 & 0.01 \\
\hline IUCD & 04 & 11 & 42 & 58 & 0.01 \\
\hline Injectables & 01 & 06 & 11 & 20 & 0.042 \\
\hline Tubectomy & 35 & 65 & 123 & 128 & 0.01 \\
\hline Vasectomy & 01 & 07 & 24 & 59 & 0.01 \\
\hline
\end{tabular}

Lack of awareness of benefits was highest in illiterates $(77 \%)$ while in the literates, irrespective of the education level, it was around $44 \%$ (statistically significant). Fear of side effects of various methods of contraception was around $14 \%$ irrespective of literacy level. Partner consent for a woman to use a contraceptive still holds a big role in our patriarchal society irrespective of her literacy level (Figure 4).

Most gave multiple reasons about its benefits. $34.5 \%$ of the study population felt contraception would avoid unwanted pregnancy and $33 \%$ felt it allows spacing. $1 / 4^{\text {th }}$ of the population, though aware of contraceptive methods, had no idea of its benefits (Figure 5).

A total $70 \%$ of the population were not aware of free availability of various methods of contraception at all government hospitals, even at our hospital (Figure 6).

A total 59 women accepted tubectomy at delivery and underwent surgery either concurrently along with Caesarean section or as puerperal sterilization. The rest of the Yes group, i.e. 133 puerperal women wanted to come for a spacing method after 6 weeks. 


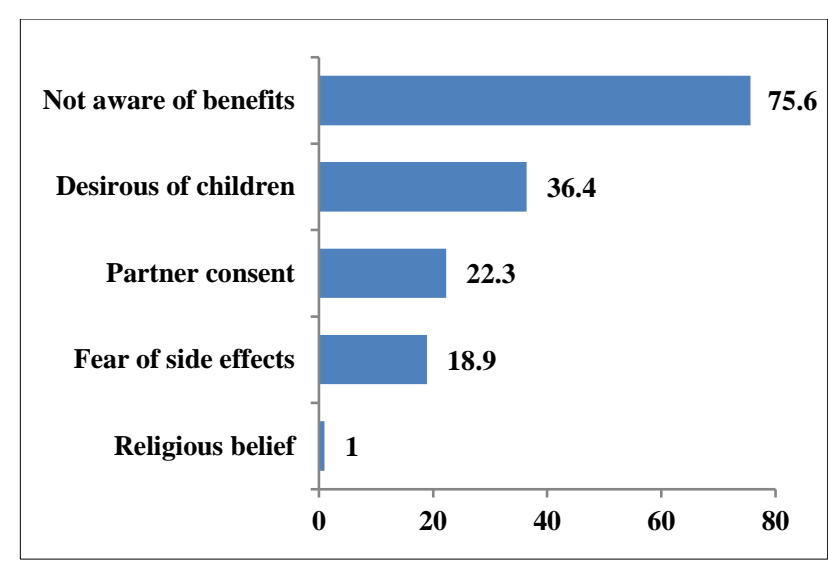

Figure 3: Reasons for not following temporary contraception in the past $(\%)(n=291)$.

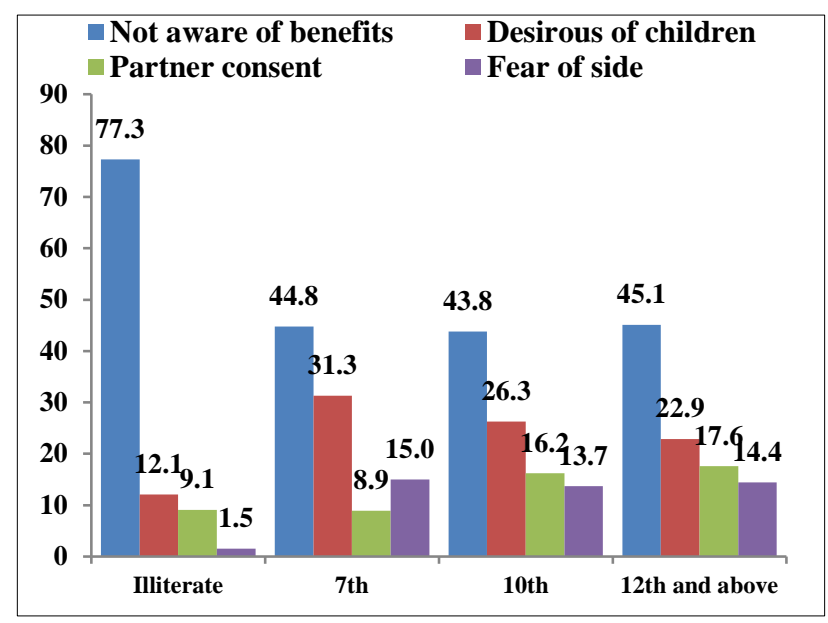

Figure 4: Literacy levels and reasons for not using temporary contraception.

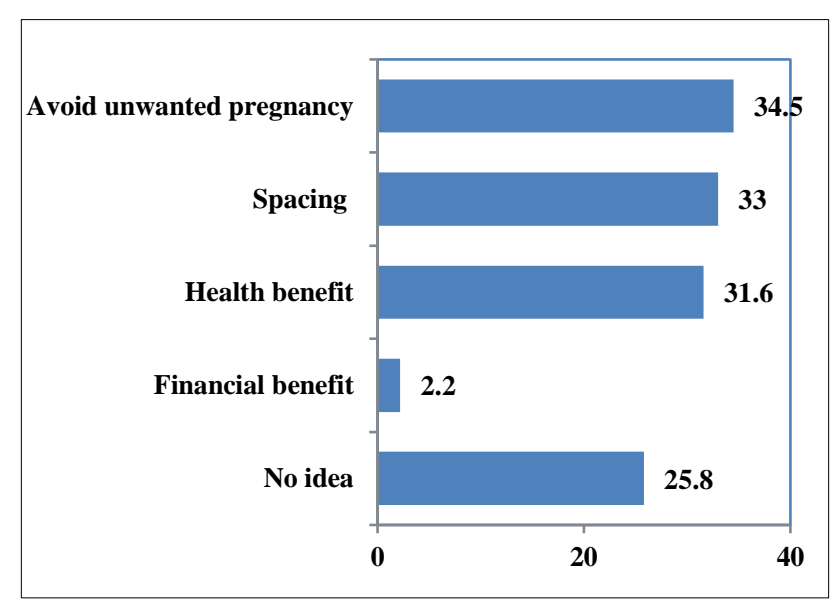

Figure 5: Purpose/benefits of using FP methods

$$
\text { (\%) }(n=446) \text {. }
$$

As is common in our country, in half the families the male spouse and other family members have the main say in contraceptive practice (Figure 7).
A total 212 of them wanted to plan about contraception later. Hence a total of 404 out of 502(80.5\%) have been motivated to use contraception after this counselling (Figure 8).

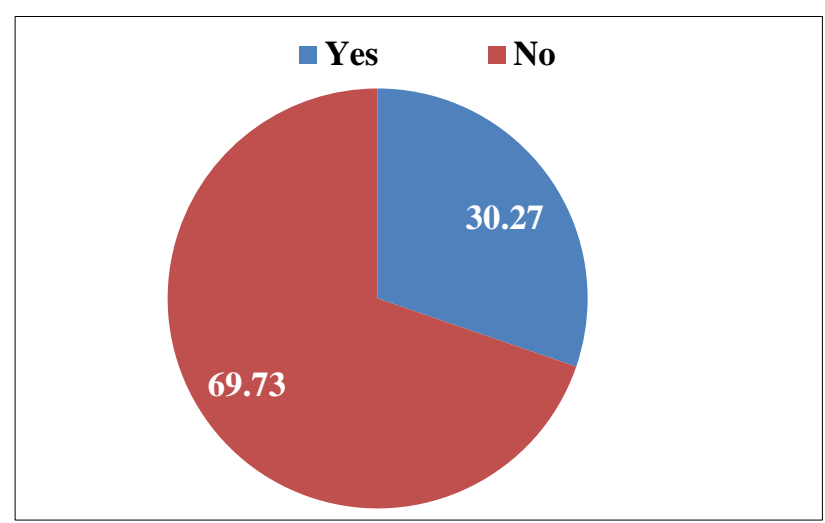

Figure 6: Awareness about free availability of FP services at Government hospitals/our hospital $(n=502)$.

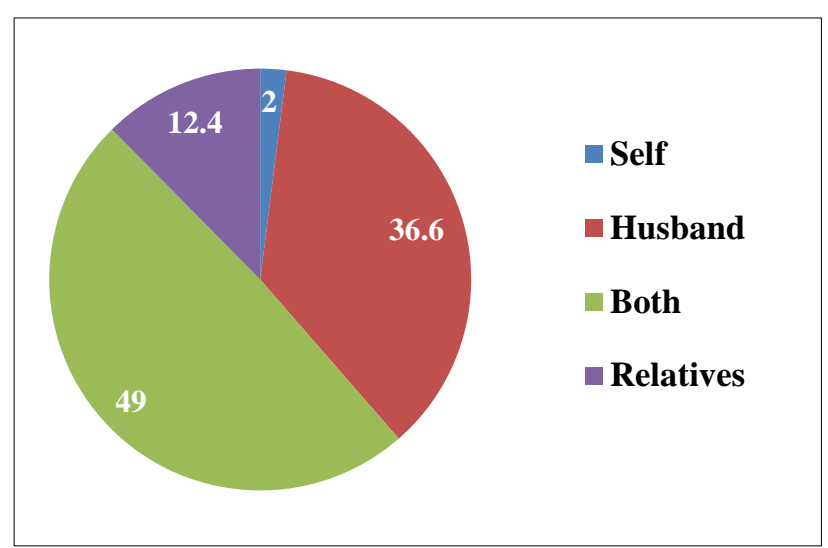

Figure 7: Decision maker for contraception use/family size $(\mathbf{n}=502)$.

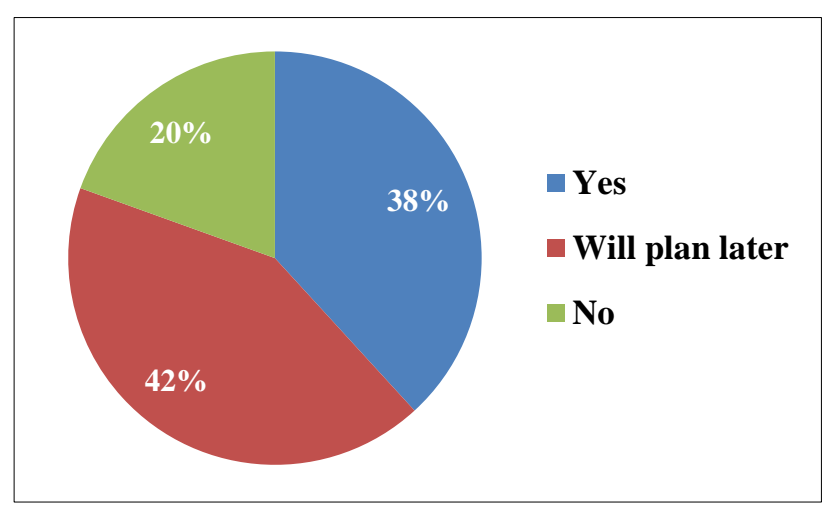

Figure 8: Willing to accept contraception now $(\mathbf{n}=502)$.

\section{DISCUSSION}

A total $55.4 \%$ of our study population belonged to agegroups 21-30 years and $43.4 \%$ were less than 20 years. In 
studies by Nair A et al at Kozhikode majority belonged to 21-25 years age-group (48\%) and by Thapa $S$ et al at Varanasi $59.1 \%$ belonged to 25 -34-year age-group. ${ }^{9,10}$

Majority in our study were uniparous $(48.6 \%)$ while it was $32 \%$ and $43.3 \%$ in the studies by Thapa $\mathrm{S}$ et al and Nair A et al respectively.

A total $14.1 \%$ of our study group were illiterate, $85.9 \%$ were educated up to class $7^{\text {th }}$ and $69.4 \%$ had at least 10 years of schooling. This was quite better in comparison to NFHS-4 2015-16 literacy rate of 61.5\% literacy among rural Indian women and $27.3 \%$ having at least 10 years of schooling. This is also similar to a study by Nair A et al in 1500 women at Kozhikode, Kerala, $86.67 \%$ were educated at least up to 10 years.

A total $74.5 \%$ of our study population were home makers as compared to $83.7 \%$ in the study by Singh $\mathrm{M}$ et al, $20.7 \%$ of our women were working as farmers/laborer's. ${ }^{11}$

Majority (59.4\%) of our study population were Hindus, $28.3 \%$ Muslims and $12.1 \%$ Christians whereas in the study by Nair A et al, $42 \%$ were Hindus, $56 \%$ Muslims and $2 \%$ were Christians.

Majority $88.85 \%$ of our women were aware of some method of modern contraceptive method which was comparable to $80 \%$ in study by Nair A et al and by Kaushal SK et al in Kanpur. ${ }^{12}$

Another study by Araoye et al, in a randomly selected population aged 18-24 in a Nigerian tertiary institution showed $98.4 \%$ of females knew at least one method of contraception. ${ }^{13}$

A total $58.7 \%$ (291 out of 446) were aware of the different temporary methods of contraception available. One third of our women $(30.85 \%)$ were aware of only the permanent/irreversible methods of female and male sterilization; and $41.3 \%$ of these women (64 out of 155) were aware of only female sterilization but never heard of male sterilization. Such an observation has not been reported in any of the earlier studies.

Most of the women in our study were aware of multiple methods of contraception. Tubectomy (female sterilization) was the method known to maximum women $78.7 \%$ and injectables were the least known method, $8.5 \%$ as compared to $80 \%$ and $26 \%$ respectively in a study by Meenakshi Singh et al from New Delhi in a cohort of 492 postpartum women. The awareness about all other temporary methods was also lower amongst our women as compared to other studies. Thapa $\mathrm{S}$ et al from Varanasi in a cohort of 230 post-partal and post-abortal women reported that awareness was highest for IUCDs $(83.65 \%)$ and about injectables was lowest at $38.3 \%$; these levels were significantly higher than in our study.
The association of literacy levels on the awareness of contraceptive methods was found to be statistically significant in our study $(\mathrm{P}$-value $=0.01)$. As the literacy levels rose, awareness about the various temporary methods and Vasectomy (male sterilization) improved.

A total $58.7 \%$ (291) of the study group were aware of the temporary methods. Multiple reasons were cited for not using any of these temporary methods in the past. $75.6 \%$ of these women were unaware of the benefits, $36.4 \%$ desired for further children, $22.3 \%$ did not use due to lack of partner consent and $18.9 \%$ due to fear of side effects.

Among the illiterates, lack of awareness of benefits of contraception was highest at $77.3 \%$, while in all the categories of literates it was around $44 \%$. $14 \%$ of the literate women in our study did not use any contraception due to fear of side effects. Our patriarchal society still mandates partner consent $(36.6 \%)$ for a woman to even use a temporary contraception.

Multiple benefits were given for using contraception. But $1 / 4^{\text {th }}$ of these 446 women, though aware of contraception, had no idea that it is beneficial to them. $70 \%$ of this group (350 out of 502) were not aware of the fact that these methods are freely available at all Government hospitals and also at our hospital.

Three television channels, controlled by the central government and freely available to all general public, continuously telecast about free availability of various contraceptives and advantages of using these methods. Lack of interest in viewing these channels as compared to the more visually attractive commercial TV channels may be a factor in not making these women aware. Also, the low socio-economic status, too busy with the mundane chores, less social interaction after marriage and lack of exposure to newspapers may all be a hindrance to awareness.

After counselling during this study, 38.2\% (192) of our women were willing to accept one method of contraception. 59 of these underwent tubectomy procedure as concurrent to LSCS or in immediate postpartum; the rest 133 women wanted to come after 6 weeks for a spacing method. This was in contrast to the national rural average of $46.0 \%$ of current use of Family Planning methods amongst married women aged 15-45 years (NFHS-4). 212 of them (42.0\%) wanted to plan about contraception later on. Hence a total of 404 out of $502(80.5 \%)$ have been motivated to use contraception after our counselling.

This study tells us that there is great unmet demand for use of contraception among rural people. And this unmet need for family planning appears to be significantly higher than the $13.2 \%$ reported amongst rural women in NFHS-4. Proper dissemination of this information by rural health workers of the PHCs, hospital staff, education material at hospitals (both written and visual) 
and emphasizing upon these at each antenatal visit will help these women to access these services.

\section{CONCLUSION}

There is a great unmet demand for contraception among rural women in India. Proper dissemination of the information about free availability of these methods by rural health workers, hospital staff and making these accessible in the peripheral areas of the country will help these couples. Providing oral, written and visual information to all the pregnant women at each ante-natal visit will be additional methods.

\section{ACKNOWLEDGMENTS}

Authors would like to thank to all the patients who trusted us all to do this study.

\section{Funding: No funding sources}

Conflict of interest: None declared

Ethical approval: The study was approved by the Institutional Ethics Committee

\section{REFERENCES}

1. United Nations Department of Economic and Social Affairs. Publications: World Population Prospects, the Revision, 2017. Available at: https://www.un.org/development/desa/publications/ world-population-prospects-the-2017-revision.html. Accessed on $6^{\text {th }}$ December 2019.

2. National Family Health Survey-4 fact sheets; 201516. Available at: http://rchiips.org/nfhs/ factsheet_NFHS-4.shtml. Accessed on $6^{\text {th }}$ December 2019.

3. Park's Textbook of Preventive and Social Medicine, $21^{\text {st }}$ Edition, Chapter 9; 2011:445.

4. Smith R, Ashford L, Gribble J, Clifton D. Family Planning saves lives. A report. Washington DC: Population Reference Bureau; 2009. Available at: https://www.prb.org/fpsl/. Accessed on $6^{\text {th }}$ December 2019.
5. Conde-Agudelo A, Belizan JM. Maternal morbidity and mortality associated with inter-pregnancy interval: cross-sectional study. $\mathrm{Br}$ Med J. 2000;321(7271):1255-9.

6. Vernon R. Meeting the family planning needs of postpartum women. Stud Family Planning. 2009;40(3):235-45.

7. John AR, William LW. Contraception use, intention to use and unmet need during the extended postpartum period. Int Family Planning Persp. 2001;27(1):20-7.

8. Singh KK, Verma S, Tanti S. Contraceptive use among postpartum women in India. Asian Population Studies. 2013;1-17.

9. Nair A, Devi S. Knowledge and attitude of puerperal women towards family planning practices in a tertiary care hospital. J Evid Based Med Health. 2017;4(5):212-6.

10. Thapa S, Rani A, Mishra CP. Knowledge, attitude and belief about contraception in postpartum and post abortal women in a tertiary care centre. Int $\mathbf{J}$ Reprod Contracept Obstet Gynecol. 2014:3(3):533-9.

11. Singh M, Mehla S, Ranjan R, Das B. Awareness and acceptance of contraception in post-partum women in a tertiary care hospital of Delhi. Int $\mathbf{J}$ Reprod Contracept Obstet Gynaecol. 2015;4(3):690-5.

12. Kaushal SK, Saxena SC, Srivastava VK, Gupta SC, Nigam S. KAP study on contraceptive methods in Kanpur district of Uttar Pradesh, India. Ind J Comm Health. 2010;22(1):33-8.

13. Araoye MO, Fakeye OO, Jolayemi ET. Contraceptive method choices among adolescents in a Nigerian tertiary institution. West Afr J Med. 1998;17(4):227-31.

Cite this article as: Nabhi VR Murty, Madhuri M, Vijayalakshmi G, Vasantha K, Kavitha K, Uma B. Awareness, attitude and practice of contraception amongst post-partum women in a rural tertiary care hospital, Telangana, India. Int J Reprod Contracept Obstet Gynecol 2020;9:38-43. 